BONAFIDE: Jurnal Teologi dan Pendidikan Kristen

www.jurnal.sttissiau.ac.id/Volume 2/Nomor 1/Juni 2021/hal.83-99

\title{
PANDANGAN IMAN KRISTEN TERHADAP ILMU PENGETAHUAN DAN APLIKASINYA BAGI PENDIDIKAN AGAMA KRISTEN
}

\author{
Jemy Noviyanto \\ Sekolah Tinggi Teologi Injili Arastamar Nabire \\ Jemywenda0712@gmail.com
}

\begin{abstract}
The struggle between the Christian faith and science throughout the history of life raises many pros and cons. But is it true that the Christian faith is against science and vice versa science is against the Christian faith? This paper aims to answer this question to provide a uniform view of Christian faith and science in the world of Christian education. The approach to writing this article is comparative book research and descriptive approach between Christian faith and science, hoping that the pros and cons between the two views, both Christian faith and science, can be accepted by these two groups. Christian Education, as a means of building students' character as believers, must provide a view based on Christian faith towards science that continues to develop. The Christian faith and the educated generation of the Church today are faced with technological advances that influence the thinking and faith that represent the current era. Christian Education must answer this through faith and science, where everything starts from faith and is developed in science. Today's current technology comes from the product of the Christian faith that believes that God created the universe and humans are equipped with intelligence. The universe provides materials that humans can develop through the mind provided by God.
\end{abstract}

Keywords: Christian faith, science, Christian Education

\begin{abstract}
Abstrak. Pergumulan antara iman Kristen dan ilmu pengetahuan sepanjang sejarah kehidupan banyak menimbulkan pro dan kontra. Tetapi apakah benar iman Kristen menentang ilmu pengetahuan dan juga sebaliknya ilmu pengetahuan menentang iman Kristen? Tujuan penulisan ini mau menjawab pertanyaan tersebut, memberi keseragaman pandangan antara iman Kristen dan ilmu pengetahuan dalam dunia Pendidikan Kristen. Pendekatan penulisan artikel ini pendekatan penelitian buku dan deskriptif komparatif antara iman Kristen dan ilmu pengetahuan, dengan harapan pro dan kontra antara dua pandangan, baik iman Kristen dan ilmu pengetahuan dapat di terima oleh dua kelompok ini. Pendidikan Agama Kristen sebagai sarana pembentukan karakter nara didik sebagai pribadi yang beriman, harus memberikan pandangan yang berdasarkan iman Kristen terhadap ilmu pengetahuan yang terus berkembang. iman Kristen dan generasi gereja yang berpendidikan dewasa ini diperhadapkan dengan kemajuan tekhnologi (era digitalisasi) yang sedikit banyak mempengaruhi pemikiran dan keimanan yang mewakili pada era saat ini. Pendidikan Agama Kristen harus mampu menjawab hal ini melalui pendekatan iman dan science, di mana segala sesuatu bermula dari iman dan di kembangkan dalam science. Tekhnologi kekinian zaman sekarang hadir dari produk iman Kristen yang percaya kepada Tuhan yang menciptakan alam semesta dan manusia yang di perlengkapi oleh akal budi. Alam semesta menyediakan materimateri yang bisa di kembangkan oleh manusia melalui akal budi yang di sediakan oleh Tuhan.
\end{abstract}

Kata kunci: iman Kristen, ilmu pengetahuan, Pendidikan Agama Kristen 
BONAFIDE: Jurnal Teologi dan Pendidikan Kristen

www.jurnal.sttissiau.ac.id/Volume 2/Nomor 1/Juni 2021/hal.83-99

\section{PENDAHULUAN}

Berpikir atau berfilsafat bagian dari hidup yang mengerahkan segenap akal pikiran manusia. Immanuel Kant berkata; "Dari saya, kalian tidak akan belajar berfilsafat. Saya mengajar kalian berfilsafat. Bukan pemikiran-pemikiran yang ditiru, akan tetapi bagaimana caranya berpikir sendiri" (dalam Q-Aness dan Hambali 2003, 1). Berpikir pada dasarnya merupakan sebuah proses yang membuahkan pengetahuan (Suriasumantri 2015). Menurut Tzu "Pengetahuan tentang peta bukanlah pengetahuan, pengetahuan sejati adalah tentang realitas itu sendiri” (dalam Q-Aness dan Hambali 2003, 48). Cosmos dan kebenaran Tuhan adalah realita yang perlu diketahui dengan jiwa dan akal. Pola berpikir manusia berbeda-beda dan Tuhan ingin akal itu digunakan dengan semestinya dalam terang Firman Tuhan sehingga akal itu dapat mengetahui rahasia-rahasia ciptaan Tuhan sehingga mengasilkan suatu ilmu pengetahuan yang berguna.

Dunia dengan berbagai ragam ilmu pengetahuan yang ada menjadikan segala sesuatu menjadi mudah dan serba praktis. Semua itu adalah hasil dari akal manusia yang adalah manusia berfikir sejak pencipatan manusia pertama. Berfikir juga untuk mengetahui pengetahuan kebenaran yang adalah Tuhan. "Menurut Socrates dan Plato memberikan kita cara mencapai pengetahuan dengan penalaran akal budi" (dalam Q-Aness dan Hambali 2003, 199). Budi sesuatu yang tertinggi dalam diri manusia yang mempunyai kemampuan untuk mengenal Tuhan.

Dalam ilmu pengetahuan pertanyaan yang sering timbul, "mengapa harus ada alam semesta? Mengapa jagat raya memiliki keteraturan (order)? Apakah alam merupakan buatan perancang yang cerdas?” (Barbour 2002, 14). Pertanyaan 
BONAFIDE: Jurnal Teologi dan Pendidikan Kristen

www.jurnal.sttissiau.ac.id/Volume 2/Nomor 1/Juni 2021/hal.83-99

ini harus dijawab melalui sudut pandang iman Kristen dan ilmu pengetahuan manusia. Dalam dunia Pendidikan Agama Kristen, iman Kristen dan ilmu pengetahuan adalah sesuatu yang harus bisa di bandingkan untuk mendapat suatu titik temu yang berguna bagi perkembangan nara didik Kristen yang ada. Mengapa harus demikian, karena nara didik Kristen bukan hanya mendapatkan ilmu pengetahuan Agama saja di lingkungan sekolah mereka namun mereka juga mendapatkan ilmu pengetahuan yang beragam.

Terkadang PAK hanya menampilkan tokoh-tokoh Alkitab dan ayat-ayat hafalan sebagai hafalan saja dan pengajaran-pengajaran yang diberikan tidak diimbangi dengan penjelasan yang mendewasakan iman Kristen mereka dan juga tidak menjelaskan bahwa iman Kristen bisa mempengaruhi perkembangan ilmu pengetahuan di dunia ini. Sehingga mereka mempunyai pemahaman yang salah bahwa iman Kristen dan ilmu pengetahuan yang mereka terima bersinggungan/berlawanan atau tidak sejalan.

Sehingga dalam tulisan ini akan menjadikan PAK sebagai tempat nara didik Kristen mengimani dengan iman Kristen dan dengan akal mereka bahwa "Allah orang Kristen adalah yang menciptakan alam semesta, bukan seperti pandangan orang non Kristen bahwa alam semesta menciptakan Allah” (Berkhof dan Til 2004, 3). Pendidikan Agama Kristen membawa nara didik kepada pemahaman yang benar tentang pribadinya sebagai manusia sesuai dengan pandangan Alkitab "bahwa manusia sebagai pelaku yang bertanggung jawab, yang setiap tindakannya didalam sejarah (waktu dan tempat) harus diarahkan dan 
BONAFIDE: Jurnal Teologi dan Pendidikan Kristen

www.jurnal.sttissiau.ac.id/Volume 2/Nomor 1/Juni 2021/hal.83-99

diadili oleh hukum Allah, suatu hukum dimana semua peraturan dan nilai-nilainya secara sadar harus diterapkan dalam hidupnya" (Holmes 2009, 104).

Tujuan dari artikel ini adalah untuk memberikan gambaran yang seragam dalam memahami iman Kristen dan ilmu pengetahuan berdasarkan sudut pandang yang terukur baik dalam perspektif iman Kristen dalam ilmu pengetahuan maupun perspektif ilmu pengetahuan dalam iman Kristen. Sehingga saat mendapatkan gambaran dari dua perspektif tersebut maka bisa di jadikan acuan untuk menerapkan dalam Pendidikan Agama Kristen. Dengan begitu Pendidikan Agama Kristen lebih efektif dalam pengajarannya bukan hanya sekedar mengisi kognitif hafalan agama, melainkan juga segi afektif dan psikomotorik nara didik tersentuh untuk merasakan iman Kristen dan mengaplikasikan iman Kristen di tengah perkembangan ilmu pengetahuan yang berkembang pesat di era sekarang ini, juga mampu menjawab science dalam perspektif iman Kristen dan tempat yang efektif adalah dalam Pendidikan Agama Kristen yang utuh.

\section{METODE PENELITIAN}

Penelitian ini menggunakan metode penelitian kepustakaan dengan analisis deskriptif. Analisis artinya; "menguraikan suatu pokok atas berbagai bagian dan penelaan bagian itu sendiri serta hubungan antar bagian untuk memperoleh bagian yang tepat dan pemahaman arti keseluruhan. (Bahasa 1990, 52). Deskriptif artinya penulis akan berusaha mendeskripsikan dan mengintepretasikan akibat yang sedang terjadi, kecenderungan yang sedang berkembang (Sumanto 1990). 
BONAFIDE: Jurnal Teologi dan Pendidikan Kristen

www.jurnal.sttissiau.ac.id/Volume 2/Nomor 1/Juni 2021/hal.83-99

\section{HASIL PENELITIAN}

\section{Pengertian Iman Kristen}

Untuk meyeragamkan pemahaman mengenai iman Kristen dan ilmu pengetahuan, maka harus dipahami secara benar pengertian keduanya. Pertanyaan antara iman Kristen dan ilmu pengetahuan bertentangan atau selaras, dan pertanyaan ini harus dijawab, untuk menjawab hal itu terlebih dahulu harus tahu dan memahami pengertian-pengertian diantara keduanya.

\section{Arti Iman}

Pernyataan iman di dalam Kekristenan harus dipahami mulai dari Perjanjian Lama sampai pada perkembangan Kekristenan sampai saat ini. Pernyataan itu merupakan sebuah ungkapan keteguhan hati Tuhan kepada umatNya dalam ikatan perjanjian. "Di dalam Perjanjian Lama kata iman berasal dari kata kerja "aman",yang berarti "memegang teguh", kata ini dapat muncul dalam bentuk yang bermacam-macam, umpamanya dalam arti "memegang teguh pada janji” seseorang, karena janji itu dianggap teguh atau kuat, sehingga dapat diamini, dipercaya . (Hadiwijono 2003, 17).

Dalam Perjanjian Lama jelas dikatakan bahwa Allah memulai perjanjianNya melalui Adam (janji induk Kejadian 3:15) dan Abraham janji keturunan bangsa-bangsa. Melalui perjanjian-Nya itu Allah mempunyai inisiatif untuk mengadakan perjanjian kebaikan kepada umat-Nya, dan perjanjian itu secara turun temurun disampaikan oleh Allah kepada umat-Nya melalui utusan-utusanNya dan melalui Kitab Suci. "Jadi iman jika diterapkan kepada Tuhan Allah, maka kata iman berarti bahwa Allah harus dianggap sebagai yang teguh atau yang kuat (Hadiwijono 2003, 17). 
BONAFIDE: Jurnal Teologi dan Pendidikan Kristen

www.jurnal.sttissiau.ac.id/Volume 2/Nomor 1/Juni 2021/hal.83-99

Di dalam Perjanjian Baru pengertian iman tertulis dalam Ibrani 11:1,2; "Iman adalah dasar segala sesuatu yang kita harapkan dan bukti dari segala sesuatu yang tidak kita lihat, sebab oleh imanlah telah diberikan kesaksian kepada nenek moyang kita." Iman adalah sebuah dasar untuk berharap dan harapan itu dibuktikan melalui cara Tuhan bekerja kepada orang-orang yang dikenan-Nya, iman juga bekerja atas kehendak Allah hanya kepada umat-Nya dalam perjanjian. "Tanpa iman, tidak seorangpun yang diperkenan oleh Allah. Maksudnya tidak ada seorangpun yang disenangi oleh Tuhan" (Tong 1996, 24). Hal ini merupakan bukti bahwa Tuhan memperhatikan manusia dengan memberi iman yang membuat manusia berkenan dihadapan Tuhan, iman syarat mutlak untuk diperkenan oleh Tuhan.

Iman sudah ditanam dalam diri manusia dengan tujuan Tuhan sendiri, ‘ tindakan Tuhan Allah yang menanamkan semacam iman dasar (iman natural) di dalam diri setiap orang (Tong 2004, 98). Dalam kamus bahasa Yunani $\pi i ́ \sigma \tau i ́ \varsigma$ mempunyai arti iman, kepercayaan, keyakinan, iman Kristen; kekuatan iman (Roma 14:22-23), ajaran (Yudas 3:20); tanggungan, bukti (Kisah Para Rasul 7:31); Janji (I Timotius 5:12). Hal ini menunjukkan bahwa iman sifatnya aktif dalam diri manusia dan manusia berhak menerima hal tersebut. Soren Kierkegaard mengatakan bahwa iman baginya merupakan suatu mujizat yang mengubah seluruh cara hidup seseorang (Raeper dan Smith 2000). Kesimpulannya adalah iman adalah suatu ketetapan yang teguh bahwa sesuatu akan terjadi menurut yang dipercayai/diimani, dan secara aktif iman bekerja untuk mengubah perilaku dan 
BONAFIDE: Jurnal Teologi dan Pendidikan Kristen

www.jurnal.sttissiau.ac.id/Volume 2/Nomor 1/Juni 2021/hal.83-99

cara pandang seseorang untuk di bawa kepada pengetahuan yang benar tentang Tuhan dan segala apa yang dilakukan oleh Tuhan kepada dunia dan segala isinya.

\section{Pengertian Ilmu Pengetahuan}

Untuk mengerti arti dari ilmu pengetahuan harus melihat kepada dua kata yang sering bersamaan disematkan yaitu kata ilmu dan pengetahuan. Dua kata yang berbeda ini sesungguhnya semuanya merupakan dari satu sumber yaitu akal. Tokoh rasionalis modern Rene Descaters mengatakan pernyataannya sebagai berikut "Cogito ergo sum, aku berpikir maka aku ada, merupakan pembuktian eksistensi manusia sebagai kesadaran" (Descartes 1995, xi). Akal merupakan bukti kesadaran manusia akan keberadaanya, kesadaran inilah yang membuat manusia berbeda dan unik dibandingkan dengan makhluk hidup lainnya.

Dua kata ini muncul secara bersamaan oleh karena memiliki keterkaitan yang berakar dari rasio manusia. Manusia menemukan jati dirinya sebagai manusia berakal melalui pengetahuan yang manusia dapat miliki, dan dari hasil pengetahuan yang manusia dapat miliki inilah manusia menyusun secara sistematis pengetahuan-pengetahuan tersebut dalam beberapa kelompok yang disebut dengan ilmu. Dapat disimpulkan bahwa ilmu adalah hasil dari pengetahuan-pengetahuan manusia. "Ilmu adalah dari suatu pengetahuan yang sudah terorganisir serta tersusun secara sistematik menurut kaidah umum" (Nazir 2007). Kaidah umum inilah pengetahuan-pengetahuan yang manusia dapat miliki, dan pengetahuan-pengetahuan inilah yang membuat manusia disebut manusia beradab, sehingga manusia selalu meninggalkan jejak-jejak peradaban sebagai bukti keberadaan manusia di bumi. Jujun Suriasumatri mengatakan bahwa dalam 
BONAFIDE: Jurnal Teologi dan Pendidikan Kristen

www.jurnal.sttissiau.ac.id/Volume 2/Nomor 1/Juni 2021/hal.83-99

keberadaanya, manusia merupakan manusia yang dikatakan sebagai manusia beradab dan ilmu itu sendiri merupakan salah satu hasil dari usaha manusia untuk memperadab dirinya (Suriasumantri 2015).

Pengetahuan merupakan suatu informasi dari refleksi manusia terhadap gejala-gejala alam atau peristiwa-peristiwa kehidupan yang dialami manusia yang dilihat sebagai suatu realita bahwa semua itu di alam sadar pikiran manusia itu sendiri. "Sumber pengetahuan yang mencukupi dan dapat dipercaya adalah rasio (akal). Hanya pengetahuan yang diperoleh melalui akallah yang memenuhi syarat yang dituntut oleh sifat umum dan yang perlu mutlak" (Hadiwijono 1980, 18)

Pengetahuan yang benar adalah jika kita berpikir secara sehat terhadap apa yang Tuhan kehendaki terhadap dunia ini, manusia pertama jatuh dalam dosa dikarenakan tidak berpikir secara sehat apa yang dikehendaki Tuhan terhadap dirinya. Menurut Louis Leahy pengetahuan dalam dirinya sendiri merupakan suatu nilai (Leahy 1997). Manusia mempunyai nilai dalam pengetahuannya yang membedakan makhluk ciptaan yang lainnya sehingga manusia mampu percaya dan melihat pernyataan Tuhan. Orang Kristen percaya kepada pernyataan Tuhan, dengan akal sehatnya orang Kristen harus mengetahui dan memahami pernayataan itu dengan baik, Agustinus mengatakan. “Orang Kristen juga percaya pada bukti adanya pikiran sehat yang dipakai oleh otak dengan bantuan seluruh tubuh;karena jika seseorang yang mempercayai pikiran sehatnya kadang-kadang masih bisa terperdaya, ia adalah orang yang paling malang, karena seharusnya ia tidak begitu mempercayakan pikiran sehatnya pada hal-hal yang indah" (Nash 2001, 54). Akal sehat digunakan untuk mengetahui pengetahuan tentang Tuhan dan segala yang sudah dinyatakan- 
BONAFIDE: Jurnal Teologi dan Pendidikan Kristen

www.jurnal.sttissiau.ac.id/Volume 2/Nomor 1/Juni 2021/hal.83-99

Nya, manusia bertanggung jawab dengan pengetahuannya yang didapat untuk menjelaskan dengan benar.

\section{PEMBAHASAN}

Segala sesuatu yang terjadi di dalam dunia ini mempunyai hubungan satu dengan yang lain, begitu juga antara iman Kristen dan ilmu pengetahuan juga mempunyai hubungan. Tuhan menciptakan dunia dan isinya dengan teratur dan semuanya dipandang Tuhan baik. Keteraturan itulah sebenarnya menunjukkan suatu hubungan atau relasi yang baik, karena tidak mungkin sesuatu yang tercipta di dunia ini tidak ada hubungan satu dengan yang lain, semua yang Tuhan berikan kepada dunia ini mempunyai hubungan yang harmonis. Iman Kristen dalam hubungan ini mempunyai peranan yang penting terhadap pertanyaan seputar ilmu pengetahuan.

\section{Menjelaskan dan Menjawab ilmu pengetahuan}

Albert Einstein berkata, “ ilmu tanpa agama buta dan agama tanpa ilmu adalah lumpuh" (Suriasumantri 2015, 3). Kebenaran keilmuan harus didukung oleh sikap kerohanian yang benar di hadapan Tuhan. Harus disadari bahwa ilmu pengetahuan juga berperan dalam proses pencarian kebenaran dan kebenaran itu adalah Tuhan dan haruslah diakui keberadaan kebenaran itu sebagai dasar ilmu pengetahuan. Iman Kristen yang didasarkan oleh pengetahuan terhadap Alkitab memang harus bisa menjelaskan ilmu pengetahuan yang terus berkembang di dunia ini. Ilmu pengetahuan dengan perkembangannya membutuhkan penjelasan 
BONAFIDE: Jurnal Teologi dan Pendidikan Kristen

www.jurnal.sttissiau.ac.id/Volume 2/Nomor 1/Juni 2021/hal.83-99

dari kita sebagai manusia yang berpikir, sebagai orang Kristen haruslah bertanggung jawab akan hal tersebut.

Kepekaan religius dan kepekaan rasional dibutuhkan untuk menjelaskan ilmu pengetahuan itu supaya menjadi jelas dan benar. Di sinilah iman Kristen sangat dibutuhkan. Hal ini membuktikan iman Kristen yang didasari oleh pengetahuan terhadap Kebenaran Firman Allah dalam Alkitab mampu menjelaskan ilmu pengetahuan, keraguan terhadap manusia itu sangat beralasan, karena manusia tanpa diterangi oleh pengetahuan Firman Allah manusia tak akan mampu menjelaskan dengan pasti. Paus Yohanes Paulus II mengatakan gereja harus bersatu dengan himpunan-himpunan ilmiah. Beliau mengatakan "kesatuan dengan integritas, antara gereja dan himpunan-himpunan ilmiah, gerakan yang dapat mengatasi fragmentasi antara mereka yang mencari kebenaran dikedalaman pengalaman dan sejarah manusia, dan mereka yang juga mencari kebenaran dalam misteri alam semesta" (Leahy 1997, 172).

Paus Yohanes Paulus II mengatakan hal ini beranjak dari hukuman keji yang diberikan kepada Galileo Galilei. Paus ingin gereja dapat mulai memisahkan hal-hal pokok dari iman dari sistem-sistem ilmiah yang khas bagi suatu zaman tertentu (Leahy 1997). Paus Yohanes Paulus II mengajak gereja dengan tekun dan rendah hati agar gereja mampu menjelaskan dan menjawab ilmu pengetahuan yang terjadi dalam sejarah perkembangan dunia ini dengan rendah hati dan samasama belajar dari semua peristiwa sejarah yang mempengaruhi perkembangan dunia. Paus Paulus Yohanes II juga pernah mengatakan dalam peringatan ultah hari mati guru gereja yang besar Albertus Magnus, "tuntutan kebenaran dari sains 
BONAFIDE: Jurnal Teologi dan Pendidikan Kristen

www.jurnal.sttissiau.ac.id/Volume 2/Nomor 1/Juni 2021/hal.83-99

yang didasarkan secara rasional, karena antara akal, yang oleh alamnya diberikan oleh Tuhan. dibekali untuk kebenaran dan dimampukan untuk pengenalan kebenaran, dan iman, yang berasal dari sumber ilahi yang sama dan segala kebenaran, tidak mampu menimbulkan konflik asasi. iman justru neneguhkan hak sendiri bagi akal alamiah" (Penyusun, n.d., 147)

Akal dan iman berasal dari sumber yang sama dan sumber itu adalah Tuhan. Tuhan secara asasi tidak mengharapkan pertentangan di antara keduanya. Iman dimampukan untuk percaya kepada Tuhan sumber pengetahuan dan menjelaskan ilmu pengetahuan yang ditemukan oleh akal manusia. Seperti pernyataan Flemming di atas bahwa keragu-raguan manusia harus dijelaskan oleh iman Kristen yang berdasarkan Alkitab demikian juga harus mampu menjawab segala pertanyaan-pertanyaan yang timbul dari manusia terhadap ilmu pengetahuan karena itulah dasar yang kuat dari iman Kristen, karena kitab suci bukan suatu himpunan pernyataan bagaikan didikte dari luar (seperti majikan mendikte sepucuk surat kepada sekretarisnya!) dan menuntut sebuah ketaatan buta para penganutnya (Leahy 1997, 95). Allah memberi kitab suci agar manusia mengetahui segala pernyataan-pernyataan-Nya yang diberikan kepada manusia. Dengan begitu manusia diharapkan akan semakin sadar akan keberadaannya di dunia ini. Iman Kristen dan ilmu pengetahuan hanya bisa di damaikan melalui Kasih. Hukum Kasih mempunyai tiga obyek pusat manusia untuk berdamai dengan Tuhan antara lain; hati, jiwa dan akal budi. Menurut Leon Morris, "kasih kepada Allah harus dengan sepenuh hati, meliputi seluruh keberadaan (eksistensi) kita dan semua yang kita miliki." Sepenuh hati atau "segenap" merupakan “- 
BONAFIDE: Jurnal Teologi dan Pendidikan Kristen

www.jurnal.sttissiau.ac.id/Volume 2/Nomor 1/Juni 2021/hal.83-99

usaha yang maksimal" (keilmuan) manusia untuk dipakai dalam memuliakan Tuhan dengan semua potensi yang ada (teknologi) (Morris 2016, 575).

Iman Kristen mempunyai suatu jawaban dan jawaban itu semuanya berasal dari Alkitab, seperti ayat di atas manusia tidak mempunyai alasan untuk menyombongkan suatu ilmu pengetahuan dan kepandaian karena semua itu berasal dari hikmat Tuhan.

\section{Membangun Karakter Beriman dan Berilmu Pengetahuan Yang Benar.}

PAK sangat penting dan dibutuhkan oleh orang Kristen. Ia merupakan tempat pembentukan karakter anak didik. PAK juga merupakan penguat gereja dalam mendidik jemaat yang baik serta mempertemukan nara didik yang berkarakter baik dengan Allah. Dalam era modernisasi sekarang ini, PAK juga harus menyesuaikan kepada pola pikir nara didik di masanya. Nara didik di masa modern lebih kritis akibat kemudahan akses sumber-sumber pengetahuan yang didukung dengan kemudahan internet. Pola berpikir lama dari guru PAK pada era modern harus mampu menyesuaikan dengan keadaan yang ada sehingga bagi peserta didik. Hutington menyatakan "modernisasi merupakan suatu poses perubahan ketika masyarakat yang sedang memperbaharui dirinya berusaha mendapatkan ciri-ciri atau karakteristik yang dimiliki masyarakat modern" (Martono 2012, 81).

Dalam buku PAK karangan Homrighausen dan Enklaar disebutkan bahwa 'Pendidikan Agama Kristen berusaha untuk mempertemukan manusia dengan Allah' (Homrighausen dan Enklaar 2015, 39). Pernyataan ini mengandung pengertian manusia Kristen yang berpengetahuan harus bertemu dengan Allah 
BONAFIDE: Jurnal Teologi dan Pendidikan Kristen

www.jurnal.sttissiau.ac.id/Volume 2/Nomor 1/Juni 2021/hal.83-99

terlebih dahulu untuk menjadi pribadi yang bertanggung jawab di dalam Tuhan (bnd. Amsal 1:7). Dalam tugas mempertemukan nara didk dengan Allah disinilah dituntut seorang pengajar untuk mengenali objeknya yaitu nara didik. Homrighausen dan Enklaar melanjutkan, 'seorang guru besar perlu mengenal mahasiswanya, dan sorang guru sekolah perlu mengetahui jiwa murid-muridnya,' (Homrighausen dan Enklaar 2015, 39).

Nara didik adalah pribadi, pribadi ini mempunyai karakter yang harus dibentuk, karakter merupakan istilah yang penting dalam pendidikan. Stephen Tong mengatakan, 'pribadi, oknum atau karakter merupakan istilah yang menunjuk kepada sesuatu yang hidup, yang mempunyai peta teladan Allah" (Setiawani dan Tong 1995, 33-34). Pendidikan Agama Kristen harus membawa nara didik dengan bekal pengetahuan yang baik dalam Tuhan untuk siap menerima atau diisi berbagai ilmu pengetahuan yang nara didik terima di lingkungan Sekolah. Tuhan menciptakan manusia secara pribadi sebagai peta teladan Allah. Menurut Stephen Tong, manusia dicipta secara pribadi, sehingga dimungkinkan mengembangkan suatu kepribadian di dunia ini (Setiawani dan Tong 1995). Nara didik Kristen harus menjadi pribadi yang beriman dan cakap dalam berilmu pengetahuan. Di sinilah peran PAK yang berbasis kepada Firman Tuhan. Dengan berbagai teori dan metode pengajarannya harus mampu memberikan tempat yang mendasar bagi nara didik Kristen untuk terbuka terhadap perkembangan ilmu pengetahuan dengan benar.

Di zaman perkembangan ilmu pengetahuan yang pesat seperti saat ini, banyak orang lupa bahwa dirinya adalah peta teladan Allah. Soren Abie 
BONAFIDE: Jurnal Teologi dan Pendidikan Kristen

www.jurnal.sttissiau.ac.id/Volume 2/Nomor 1/Juni 2021/hal.83-99

Kierkegaard memberi peringatan untuk abad 19; "Bahwa di abad yang akan datang, manusia akan dijadikan mesin atau sebagian dari mesin, diseragamkan sehingga akan menghilangkan semua kepentingan individu, maka manusia akan masuk di dalam suatu kerutinan dan akan kehilangan dirinya sendiri. Manusia akan tenggelam di dalam arus masal" (Setiawani dan Tong 1995, 49). Hal semacam ini tidak bisa dipungkiri lagi dan sudah terjadi, jika seorang pendidik Agama Kristen tidak mempunyai jiwa yang luas maka mereka akan dianggap berdongeng untuk anak kecil. Pokok-pokok iman Kristen yang diajarkan tidak memperlihatkan suatu realita dibandingkan dengan pendidikan sekuler.

PAK sekarang ini menghadapi problematika realita dunia dengan ilmu pengetahuan yang terus berkembang pesat. PAK dituntut membawa nara didik kepada iman Kristen yang rasional maksudnya, yaitu iman yang disertai dengan akal yang benar. PAK harus membawa nara didik untuk mencintai Tuhan terlebih dahulu sebelum manusia mencintai kemanusiaan mereka sehingga pengetahuan tentang Allah dan manusianya dapat seimbang. Pascal mengatakan, "hal-hal yang manusiawi harus diketahui terlebih dahulu baru bisa dicintai, tetapi tidak demikian halnya dengan yang ilahi. Hal ilahi harus dicintai terlebih dahulu baru kemudian diketahui” (Cupples 1994, 70).

Perkembangan ilmu pengetahuan yang begitu pesat seperti saat ini, kiranya PAK diharapkan mampu menjadi sarana penyaring agar nara didik menerima kebijaksanaan atas perkembangan ilmu pengetahuan yang ada sampai saat ini. Iman yang mempengaruhi perkembangan ilmu pengetahuan terhadap nara 
BONAFIDE: Jurnal Teologi dan Pendidikan Kristen

www.jurnal.sttissiau.ac.id/Volume 2/Nomor 1/Juni 2021/hal.83-99

didik. Manusia diharuskan menyaring data menjadi informasi, informasi menjadi pengetahuan, dan pengetahuan menjadi kebijaksanaan (Harari 2018).

\section{KESIMPULAN}

Hubungan antara iman dan ilmu pengetahuan sering menimbulkan pertanyaan. Hal ini diakibatkan iman hanya membutuhkan kepercayaan sedangkan ilmu pengetahuan berhubungan dengan dunia realita. Untuk itu diperlukan penghubung yang benar, yaitu iman Kristen.

Sejak manusia jatuh ke dalam dosa maka pikiran dan pengetahuan telah tercemar. Sebab itu itu proses berpikir manusia perlu disertai terang Firman Tuhan sehingga hasil dari pemikiran itu dapat menolong orang banyak, bukan sebaliknya. Iman harus sejalan dengan pikiran dalam tindakan yang benar di hadapan Tuhan. Iman menuntun akal untuk bertindak secara bijaksana (Amsal 2:6) sehingga apa yang ditemukan akal dengan ilmu pengetahuan yang ada dapat berguna bagi dunia.

Dalam dunia pendidikan, Pendidikan Agama Kristen berfungsi untuk mengontrol agar pendidikan sekuler tidak membawa kepada antroposentrime yang cenderung meniadakan Tuhan. Dengan begitu, PAK mampu menjelaskan dan menjawab tantangan ke depan menghadapi perkembangan dunia ilmu pengetahuan.

PAK harus bisa membawa nara didik Kristen kepada iman Kristen yang rasional yang berarti bahwa pengetahuan mereka harus dibawa kepada iman yang benar sehingga pengetahuan yang mereka dapat bermanfaat bagi dunia. Dalam hal ini PAK membentuk nara didik Kristen yang bertanggung jawab kepada bangsa 
BONAFIDE: Jurnal Teologi dan Pendidikan Kristen

www.jurnal.sttissiau.ac.id/Volume 2/Nomor 1/Juni 2021/hal.83-99

dan mampu membawa bangsa kepada suatu peradaban yang ber-Tuhan dan tetap semangat menginjili ditengah-tengah dunia antroposentris untuk membawa kembali kepada Kristus sebagai Tuhan Juruselamat.

\section{DAFTAR PUSTAKA}

Bahasa, Pusat Pembinaan Pengembangan. 1990. "Kamus besar bahasa Indonesia (KBBI)." Jakarta: PT Gramedia. https://kbbi.web.id.

Barbour, Ian G. 2002. Juru Bicara Tuhan: antara Sains dan Agama. Bandung: Mizan.

Berkhof, Louis, dan Cornelius Van Til. 2004. Foundations Of Christian Education. Surabaya: Momentum.

Cupples, David. 1994. Beriman dan Berilmu. Jakarta: BPK Gunung Mulia.

Descartes, Rene. 1995. Risalah Tentang Metode. Jakarta: Gramedia Pustaka Utama.

Hadiwijono, Harun. 1980. Sari Sejarah Filsafat Barat. Yogyakarta: Kanisius.

—. 2003. Iman Kristen. Jakarta: BPK Gunung Mulia.

Harari, Yuval N. 2018. Homo Deus: Masa Depan Umat Manusia. Bandung: Pustaka Alvabet.

Holmes, Arthur F. 2009. Segala Kebenaran adalah Kebenaran Allah. Surabaya: Momentum.

Homrighausen, E.G., dan I. H. Enklaar. 2015. Pendidikan Agama Kristen. Jakarta: BPK Gunung Mulia.

Leahy, Louis. 1997. Sains Dan Agama Dalam Konteks Zaman Ini. Yogyakarta: Kanasius.

Martono, Nanang. 2012. Sosiologi Perubahan Sosial: Perspektif Klasik, Modern, Posmodern, dan Poskolonial. Jakarta: Raja Grafindo Persada.

Morris, Leon. 2016. Tafsiran Injil Matius. Surabaya: Momentum.

Nash, Ronald H. 2001. Iman dan Akal Budi. Surabaya: Momentum.

Nazir, Mohammad. 2007. Metode Penelitian. Jakarta: Ghalia Indonesia.

Penyusun, Tim. n.d. PAK. Pematangsiantar: STT-HKBP \& FKIP Nommensen.

Q-Aness, Bambang, dan Radea Juli A. Hambali. 2003. Filsafat untuk Umum. Jakarta: Kencana.

Raeper, William, dan Linda Smith. 2000. Ide-ide Filsafat dan Agama, Dulu dan Sekarang. Yogyakarta: Kanisius. 
BONAFIDE: Jurnal Teologi dan Pendidikan Kristen

www.jurnal.sttissiau.ac.id/Volume 2/Nomor 1/Juni 2021/hal.83-99

Setiawani, Mary, dan Stephen Tong. 1995. Seni Membentuk Karakter Kristen Hikmat Guru Dan Ayah Bunda. Jakarta: Lembaga Reformed Injili Indonesia.

Sumanto. 1990. Metodologi Penelitian Sosial dan Pendidikan: aplikasi kuantitatif dan statistika dalam penelitian. Yogyakarta: ANDI Offset.

Suriasumantri, Yuyun S. 2015. Ilmu dalam Perspektif. Cet. 19. Jakarta: Yayasan Obor Indonesia.

Tong, Stephen. 1996. Iman, Rasio dan Kebenaran. Jakarta: Institut Reformed Injili Indonesia.

—. 2004. From Faith To Faith. Surabaya: Momentum. 